\title{
Application of Computer Network Information Resources in Physical Education
}

\author{
Sun Bin, Zong Yan, Zhao Zhiming \\ Zaozhuang Vocational College of Science \&Technology, Tengzhou, Shandong, 277500, China
}

Keywords: physical education; computer; network information resources; application

\begin{abstract}
With the rapid development of modern information technology, Internet technology has been widely used throughout the country. All industries reform and innovative working methods relying on computer network, and the education industry is no exception. In the face of the age of information and networking, physical education should actively use the digital resources of computer networks to constantly innovate educational concepts, and cultivate sports professionals who are suitable for the development of the new era. Reforming physical education teaching models and teaching methods from the application of computer network in physical education is to enhance students' ability to learn independently, and to build a digital physical scientific research information platform. Based on this, the paper first elaborates the meaning and characteristics of computer network information resources, and then analyzes the application of computer network information resources in physical education, hoping to have significance and reference value.
\end{abstract}

\section{Introduction}

Since the beginning of the new century, computer information technology has developed rapidly. The technological revolution centered on the computer network information has changed or is changing people's living habits and working methods. With the development and utilization of modern network information resources in the education industry in the new era, new changes have taken place in China's physical education. The spread of various advanced education concepts has greatly promoted the development of physical education [1]. Modern network information resources are applied in every aspect of physical education, which is an inevitable factor affecting the reform of sports in the new century. How to better integrate physical education and computer network information resources is the key direction of the development of physical education at the current stage, and it is also the new goal of physical education in the new era.

\section{The connotation and characteristics of computer network information resources}

\subsection{The connotation of computer network information resources}

From a broad perspective, computer network information resources are all kinds of information that exist in the network. The scope of resources involved is very broad. It not only refers to basic visual information such as texts, pictures, and videos, but also includes professionals who provide jobs related to network information and who develop network information application technology. This kind of resource contains a wide range of types and a wide range of resources. It is a kind of resource suitable for development in the new era. From a narrow sense, computer network information resources are resource databases, including basic information data such as text, images, sounds, etc. This means the value of the network information resources themselves.

Computer network information resources have developed relying on computers as the carrier, which can be used widely. All kinds of resources are well divided objectively. It is the most promising network in our country and also the most advanced network at the present stage. People can browse a variety of information in the network communication, exchange their own ideas and express their views on specific events. This kind of application is increasingly favored by everyone. Network information has become an important driving force for the development of the national economy. Network information occupies an important position in people's daily lives and plays an increasingly important role. There are differences between computer network information resources 
and traditional resources. The content and scope of the network information resources have covered traditional information technologies. The network information that we all believe is generally used as a carrier to convey information to everyone in the form of text, pictures and sounds [2]. In simple terms, network information resources are all resources that can be used by people in computer networks. They show the intrinsic links between specific things, and involve many aspects such as economy, politics, culture, military and education.

\subsection{The characteristics of computer network information resources}

\subsubsection{The external performance features of network information resources}

Firstly, a huge amount of information. Computer network is a huge data resource pool with diverse information. It includes a wide range of scope and a variety of languages. All information that people can present in their brains can be searched on computer networks. Secondly, various types of information. Computer network information resources have a variety of language forms of expression. Without being restricted to the limitations of people's input language, they can find the desired content in the network information resources. The input person can inquire about his desired knowledge at any time. Thirdly, computer network information resources are updated quickly. No matter where the hot news happens anywhere in the world, the content will be updated as soon as possible. People can get news anywhere in the world without leaving the house. Fourth, the complex data information on computer networks is not set to meet the standard. Compared with newspapers and magazines, there are no strict audits and screening. Therefore, not all information on the network is authentic and trustworthy and the quality of network information is uneven. Fifth, information on the Internet is shared for all the public [3]. It can be viewed on the web and can be browsed directly. Sixth, the utilization rate of network information is high but the cost is low. Users can obtain the available information without paying too much money.

\subsubsection{The intrinsic characteristics of the computer network information resources}

First, in the application of network resource information, the use of computer information resources has been popularized throughout the country. In terms of economy, life and education, computer network has been introduced. Through the power of network information resources to complete all the tasks that need to be completed. Secondly, in terms of computer network information resources construction, network information technology has spread throughout the world at present. In the process of the development of network information, the construction of the network is also burdened with heavy pressure in the market environment. This is mainly due to the fact that no standardized system has been established during the initial period of network information construction. Finally, in the application of network technology, many knowledge and applications are optimized during the exploration process. Although the network has been popularized in various industrial fields, the goal of truly achieving scientific and rational application needs further deepening. If we can achieve the application of the network in the right place, then the degree of civilization of the country's development will be upgraded to a level. In addition, the network pays more attention to the construction of services at this stage, and has made progress in gradual improvement. The environment for the construction of network information resources has been continuously improved with the accumulation of experience, allowing more network resources to realize its own value.

\section{The application of computer network information resources in Physical Education}

\subsection{Change the traditional physical education teaching mode, and improve the quality of physical education and teaching efficiency}

With the arrival of the age of information and digitization, computer networks have entered the classroom teaching of physical education in schools, and they plays a more and more important role in the research and development of physical education in schools. As a modernization product, network information resources are of great importance in the education industry, and so is physical 
education. At this stage, the traditional sports teaching mode is dominated by the self-view teaching mode. That is to say, the key points of action are explained first, then the physical education teacher demonstrates and shows them to the students. This teaching mode is easy to have obstacles when students practice. Because the teacher's demonstration is immediate, the memory of the student cannot always stay in the original stage. When the specific decomposition action is vague, it will be limited by time and space [4]. It is impossible to master the essentials of learning. These existing problems will have a negative impact on the quality of the final teaching. But the use of computer network information resources can direct display the actions to be learned in the classroom, and the slow-motion is displayed in an intuitive and dynamic teaching format. This allows students to clearly grasp the appearance of each action and improve students' self-confidence in learning.

\subsection{Promote the learning and training of physical education teachers}

The cultivation of professional sports talents is closely related to the role played by teachers. Teachers are leaders and helpers of student learning. With the continuous supplement and enrichment of physical education, computer network information resources have adapted to the requirements of physical education in the new era, physical education teachers should be more aware of the task of cultivating sports professionals at the new era, and use the latest sports network information resources to combine the needs of the development of era, and constantly explore a sustainable development path. In the era of rapid information, PE teachers should establish the concept of lifelong learning and place themselves in the process of computer network information resources and become the most critical part. With the application of computer network information resources in physical education, it is difficult for PE teachers to adapt to the needs of sports development in the new period. In the specific teaching, it is necessary to strengthen their own information construction to provide support for the development of students. Physical education teachers need to improve their own sports theory knowledge system, promote their own continuous development in physical education, and better stand in the forefront of the development in the new era, and better train modern sports personnel.

\subsection{Improving students' self-learning ability}

There are a large number of available parts of physical education in computer network information resources. Students can achieve the goal of autonomous learning in network sports information resources, and it is helpful to cultivate students' learning ability and plays an irreplaceable role. There are many types of information resources in computer networks. Considering the needs of students with different degrees of learning and different levels of learning resources, students should search for suitable learning materials according to their actual situation. In the process of using the network, the communication between teachers and students was successfully completed, replacing the traditional single, fixed and boring physical education model [5]. Using modern information technology to vividly display multimedia courseware has inspired students' interest in learning, and allowed students to transform from passive learners to knowledge bearers, and improved the ability of independent learning.

\subsection{Establishing a platform for the development of physical teaching and research system}

In the era of knowledge explosion, computer network information resources are constantly updated and enriched with the development of the times. Its efficient network information resource transfer method has been integrated into the modern education industry and plays a crucial role in promoting the research and development of sports science and technology. Through the use of computer network information resources, a systematic sports education research and teaching platform will be established. In the course of the construction of the platform, we should fully absorb the favorable content of the computer network information resources, construct the system of sports scientific research and development to serve the scientific research of sports construction, and play a constructive and practical role in sports development. In the era of digital information, traditional methods of physical education have been unable to meet the speed of knowledge replacement and the changing standards of competitive sports. The modern computer network is 
already a global information resource carrier. It has a strong scientific research force and comprehensively absorbs the research institutes and library information resources of various schools. It presents a wide variety of types of education, such as online education, e-books, online libraries, academic literature, and software resources. Through the sharing of these various forms of network resources, it delivers the latest news and timely reviews the latest research developments in sports science [6]. For example, you can choose to participate in all kinds of large-scale scientific research organization exchange activities on the Internet, effectively browse various major competition information, and access various literature and materials, which lays a solid foundation for physical education teaching and research.

\section{Conclusions}

In summary, computer network information resources have been widely used in physical education at this stage. We should correctly understand the important role played by modern information technology in physical education. Even though network information resources are enriched, we must apply them based on the rationalization of physical education. In order to give full play to the value of computer network information resources, as physical education teachers, we should follow the development of the times to fully grasp the skills of using network information resources, fully invest in the work of physical education and sports research, and provide support for the rational and effective use of computer network information technology.

\section{References}

[1] Yang Yonghong. The application of Internet technology in Physical Education in Colleges and Universities[J]. Chinese information,2016, (2):253.

[2] Shao Yongxiang. Research on the application of network education technology in College Physical Education Teaching[J]. Journal of Jiamusi Education Institute,2016, (12):384.

[3] Wang Linlin. Research on the application of network education technology in College Physical Education Teaching[J]. Sports time,2017, (17):149.

[4] Du Hong. Analysis of the application of network education technology in College Physical Education Teaching[J]. Journal of Hunan City University (natural science),2016,25(6):155-156.

[5] Cui Bo. Feasibility analysis of the application of modern information education technology in physical education teaching in Higher Vocational Colleges[J]. Science \& Technology of Stationery \& Sporting Goods,2017,16(16):112-113.

[6] Cui Bo. Experimental research on the application of modern information technology in physical education teaching in Higher Vocational Colleges[J]. sports,2017, (12):119-120,84. 